\title{
Correspondence
}

\section{Optimal interval between curare pretreatment and succinylcholine}

To the Editor:

I read with interest the paper by Horrow and Lambert $^{1}$ on the optimal interval between the pretreatment dose of d-tubocurarine (dTC) and succinylcholine administration to prevent muscle pains. Having suffered personally from succinylcholine-induced muscle pain it is my practice to pretreat all patients who are to receive the drug. I warn the patients that they will develop double vision and do not proceed with the induction until they report its presence. Double vision usually develops between two or three minutes after the administration of dTC. If double vision does not occur or if pressure of time necessitates an earlier induction then the fasciculations are usually not abolished.

The presence of double vision confirms the onset of action of dTC and is preferable to an arbitrary time limit which makes no allowance for differences in circulation time and other factors influencing the onset of neuromuscular blockade.

\section{C.D. Hanning B SC MB BS FFRCS}

University Department of Anaesthesia

Leicester General Hospital

Leicester, England

LE5 4PW

\section{REFERENCE}

1 Horrow JC, Lambert DH. The search for an optimal interval between pretreatment dose of d-tubocurarine and succinylcholine. Can Anesth Soc J 1984; 31: 528-33.

\section{REPLY}

We appreciate Dr. Hanning's thoughtful comments. He raises two separate issues. The first, can succinylcholine- induced fasciculations be eliminated by assuring the onset of double vision following d-tubocurarine (dTC) administration as well as by allowing at least three minutes between the dTC and subsequent succinylcholine administration? Secondly, and only implied in Dr. Hanning's letter, will abolition of fasciculations prevent post-succinylcholine myalgias?

Dr. Hanning presents persuasive arguments relating double vision induced by dTC to the prevention of fasciculations. We are not aware of any data, including our own, that support or refute this association. Our research does indicate that if one elects to wait up to seven minutes for the onset of double vision after $d T C$, then the onset and recovery of succinylcholine neuromuscular block will not be modified.

The association of fasciculations and myalgias is a more debatable issue. Our study confirmed others that failed to show that elimination of fasciculations prevents myalgias. We warn against liberal interpretations of $D r$. Hanning's observations. Although diplopia may be an ideal marker in the prevention of visible fasciculations, prevention of myalgias as well is a less likely benefit.

Dr. Hanning's clinical observations deserve a controlled study so that they may be properly validated.

Jan Charles Horrow MD

Department of Anesthesiology

Hahnemann University

Philadelphia, Pennsylvania 19102

Donald Lambert PH D MD

Department of Anesthesia

Harvard Medical Shool

Boston, Massachusetts

\section{Colour coding of stopcocks used in pressure monitoring systems}

To the Editor:

Accidental intraarterial injection of drugs ${ }^{1,2}$ is unfortunately not a complication of the past. Commonly, both arterial and central venous pressure lines are connected to transducers with identical non-distensible tubing systems for pressure moni- 